\title{
2003 British Dental
Annual Conference
}

Elinor Parker

This year's BDA conference, held at Manchester, proved another great success. The $23 \mathrm{rd}-26$ th April were dedicated to a pertinent theme: 'embracing change.' As usual, there was much to do and see keeping the three days full and interesting.

The spy who...

The conference opened in style with the keynote speech by Dame Stella Rimington, the first woman to head MI5, and to be publicly named. She displayed great authority and charisma, whilst telling the capacity audience absolutely nothing about the secrets she knows. Her brief was to talk about change and it took her through the culture changes in MI5 as demonstrated by her own rise from 'someone's wife', to head of the service. Everyone who heard her agreed that her impressive delivery, without attentionseeking gestures and aids, was aweinspiring.

\section{Amalgam-free?}

Professor Joost Roeters and Dr Niek Opdam based their controversial and compelling lecture on the 'Amalgam-free dental school' of Nymegen on a hierarchy of types of evidence. Their change was evolutionary, driven by clinical experience and accumulating evidence, not by environmental or regulatory pressure, and they focused on how every single piece of research that they cited ranked as evidence. They showed how, by using adhesive dentistry alone, they conserve tooth structure; reduce the need for crowns and root treat-

\section{IT'S A FACT!}

- A total of 2,807 delegates attended the conference.

- There were 99 exhibition stands and 10 table top displays in total.

- The most popular session was 'The art of endodontics: system-based shaping, cleaning and obturation' presented by Stephen Buchanan from California, USA on Friday 25 April when 921 people attended.

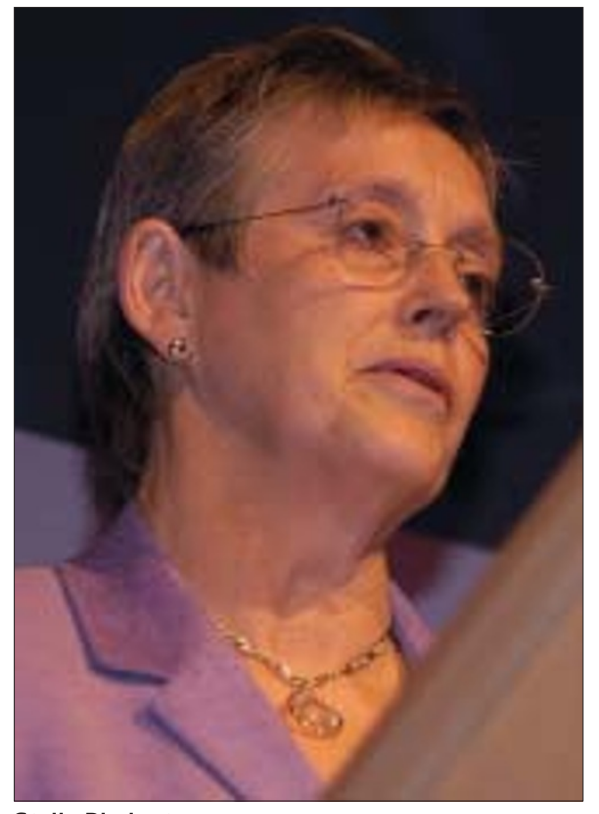

Stella Rimington

ment; save cracked teeth; compensate for extreme tooth surface loss and restore the original strength of a tooth. They showed cases of 'unsupported enamel' which had survived for 30 years with adhesive restoration, and contrasted these with cusp fractures around large amalgams which, they asserted, should be counted as failures of the restoration.

One example they showed, the restoration of six upper anteriors which had worn down almost to gum level, was enough to make me rethink my whole philosophy of practice. With no mechanical preparation, adhesive build-ups of these teeth lasted for nine years before a single one was lost, and the other five are still intact after ten years. No root canal treatments, no posts, no crowns, reasonable aesthetics, limited chair time and low cost.

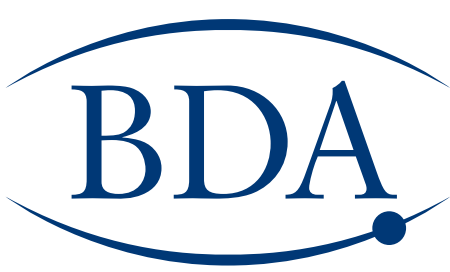

This excellent presentation also considered choice of filling materials, producing good proximal contacts and adhesive systems. For posterior strength, a heavily filled composite is indicated. Unfortunately many manufacturers have discontinued these materials in favour of 'universals' with better aesthetics but poorer mechanical properties, often without adequate clinical trials. The speakers' clear explanation of the mechanism of bonding made their recommendation of the total etch technique over self-etching one-step and one-component systems, very persuasive. Total etch, even over vital exposures, displaces the use of glass ionomer linings, so chairside time is not increased.

Some of their impressive data included the fact that restoring cracked teeth without removing the prejudiced cusp resulted in 95\% of patients reporting

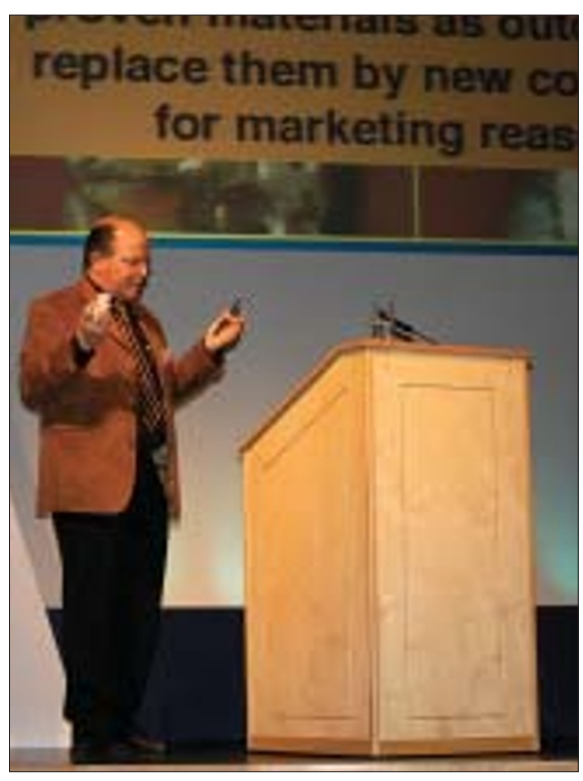

Dr Nick Opdam 


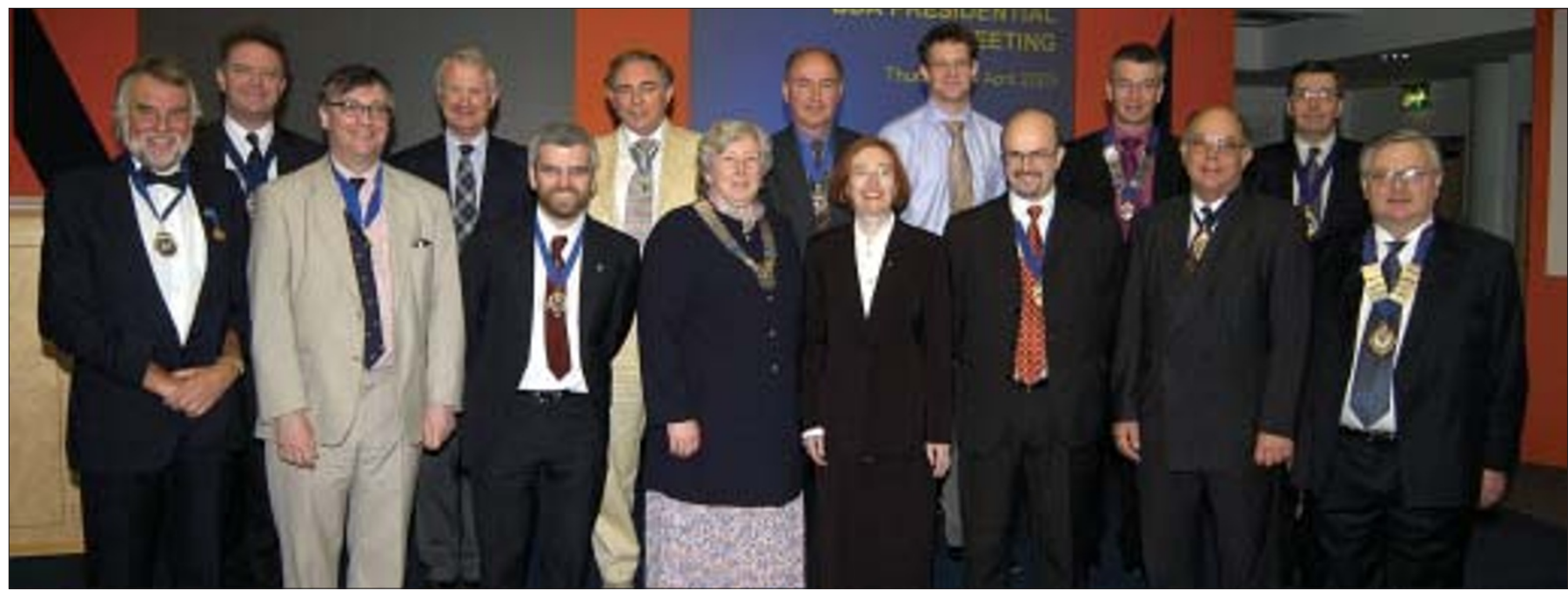

BDA Branch and Division Presidents

major improvement within one week and 75\% being totally symptom-free after six months. To convince the doubters they showed that even student-placed posterior composite fillings had an overall fiveyear survival rate of $82.5 \%$ and that qualified dentists' rates were now 91\%, the same as their contemporaneously placed amalgam restorations. Compelling indeed.

\section{Hot tips}

In contrast, I thought the 'hot tips' session was a less satisfactory experience for many of those who crowded into this increasingly popular event. The organisers had scheduled it into a larger hall than before, and a video link to an overflow venue was wisely provided. Andrew

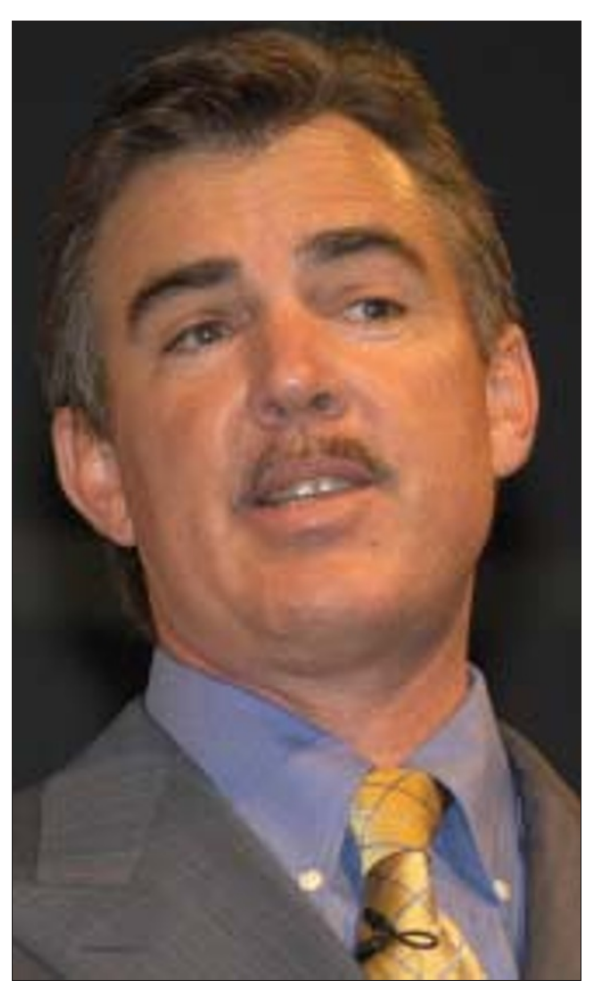

Dr Buchanan, endodontist from California
Keetley's wonderfully amusing, egalitarian, and totally concise romp through eight practical topics was what the troops go to this session to hear. Dr Sarah Pinkerton, GDP from Lisburn, Northern Ireland, praised Helen Harrison's presentations on ozone and Tabassum Khaki, 4th year student at Manchester, singled out the endodontics topic as helpful. However, Kevin Lewis had allowed himself to be drafted in to fill a slot, but agreed that his well-worn advice on the pitfalls of cosmetic dentistry was not appropriate to the 'hot tips' brand. Tony Kilcoyne's presentation was more of a ramble through the problems of dealing with anxious patients, and 'Working' accounts for the GDP' by Leo Jurkiw, an account of using spreadsheets to obtain current financial information, had a mixed reception: the 'computer whizzes' felt it was too simple and the uninitiated were probably lost after the first on-line example. But the nub of this format is, "here's how I do it, it might work for you" which is what a lot of the audience really want to hear.

\section{Endodontics}

"If a clinician is doing something that works, find out why, rather than condemn it" was Dr Stephen Buchanan's challenge to academics. Dr Buchanan, an endodontist from California, combines clinical research and teaching with private practice. His challenge refers to the dilemma of either being limited to only those techniques hallowed by long-term results or to experimenting on one's patients with every new and untried method or material. Surely the answer can lie somewhere in-between?

Dr Buchanan steered cleverly into the controversial-but-justifiable sector. Common sense has to support his contention that the body can cope with a file going through an apex when it will happily heal after apical surgery or survive an acupuncurist's needles. In fact Dr Buchanan claimed that "there is no study to show harm from penetrating the apex". His computer-generated 3D images of teeth were stunning and worth a whole term's dental anatomy lectures. An upper molar rotated in space showing its external morphology in huge detail. The apical foramen of one root appears and the viewer flies through it into the cathedrallike space of the root canal system and up into the pulp chamber, every feature of the internal anatomy gliding by in beguiling colour.

Tips on endodontics from Dr Stephen Buchanan

- Always use lubrication, it doesn't matter what, KY Jelly is fine!

- Apex locators save time and rapidly pay for themselves, but only $10 \%$ of dentists currently use them.

- Shaping canals is crucial. A tapered shape is easy to fill and is in harmony with root canal anatomy.

- Push-pull filing makes for perforations, stripping and blockages. Use tiny turns on files to avoid fracturing them.

- Use a paper point to check finally for filling length. The tiny moist tip section is a more accurate guide in a wellcleaned canal than any radiograph.

- If the nerve is vital you can treat it to any length and get success. "This is sometimes called vital pulpotomy."

- Eugenol in a sealant is only irritant if not completely set.

- Tell the patient to expect pain for 48 hours, to use analgesics and not to expect complete resolution for three weeks. Usually they will have no postoperative pain at all! 
DENTAL CONFERENCE

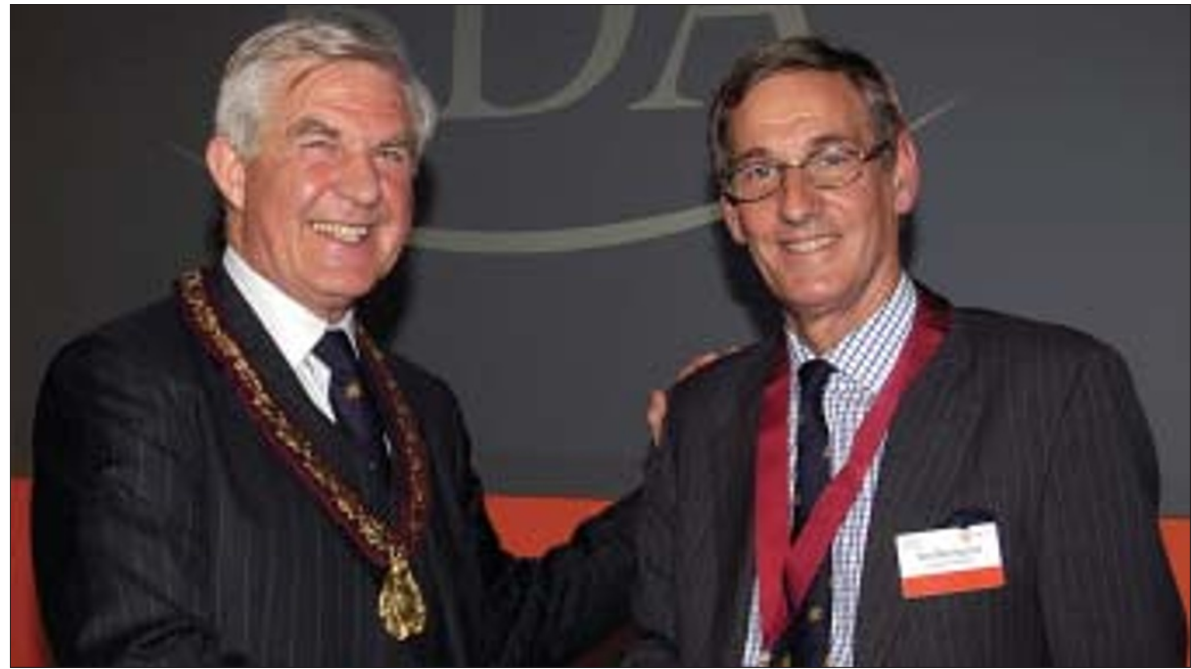

Current presidents lan McIntyre (left) and past president lan Benington (right)

The educational aim was that "practitioners address the full range of the anatomy of the root canal system". His wholeday presentation concentrated on access, instrumentation, preparation and obturation, taking diagnosis as given. Admitting that "access procedures are the hardest thing I do", Dr Buchanan stressed the importance of straight-line access to each canal. However, he was protective of the future fracture resistance of the tooth and warned against over-large openings and the dangers of perforation, advising the exclusive use of round-ended burs. The second cause of failure is root fracture. Producing an easy, drop-in access to the canals may mean an opening close to a cusp in molars or the incisal edge in incisors, but compromising on this will predispose to files fracturing as they bend into the canals. Whilst celebrating the big advances due to endosonics, the speaker asserted that the crucial element is "not the file, technique or filling material, but your ability to find all the canals, treat them and get good coronal seal."

"Where to finish at the apex is not the most important factor" he maintained. In

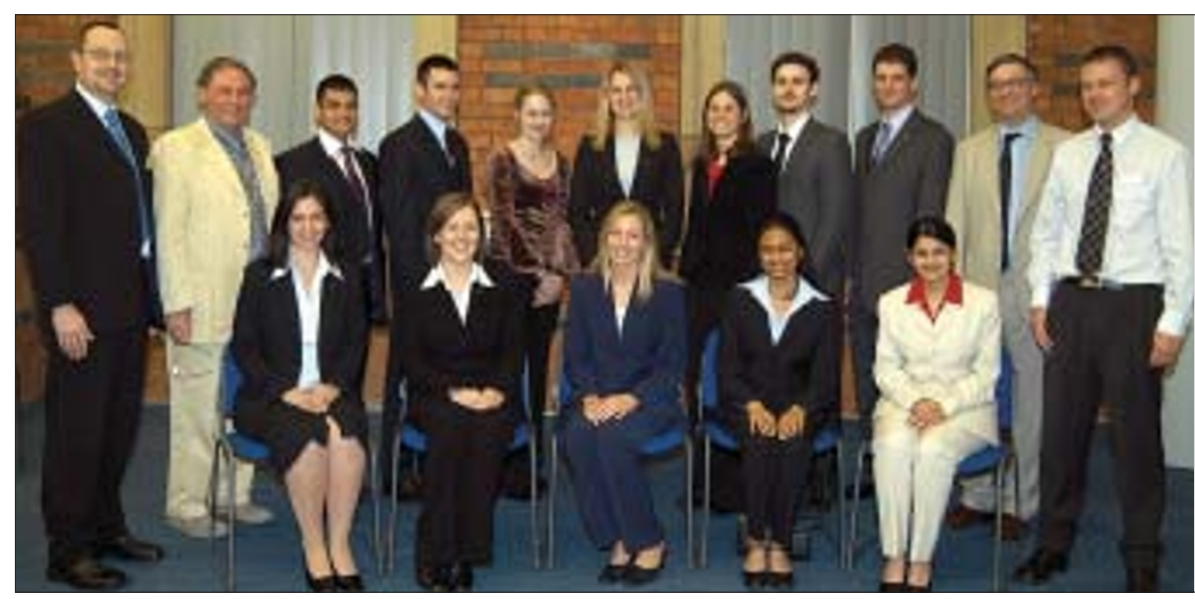

Entrants of the 2003 BDA/Dentsply Student Clinician Programme, pictured with David Walton of Dentsply (far left), Richard Gott of the BDA (far right) and the adjudicators Newell Johnson (2nd left) and John Drummond (2nd right). support of which he showed a delightfully encouraging series of his own and worldwide expert colleagues' worst results in terms of apical extrusions. Slide after slide drew gasps from the audience as huge puffs of sealer and contorted lengths of gutta percha were seen to have been happily asymptomatic for many years. In contrast, a very small length of untreated main or accessory canal can spell pain and failure. There were more 'hot tips' in half of Dr Buchanan's day than in several other lectures put together.

\section{Prosthesis}

Professor Fraser McCord started his presentation by admitting that complete denture prosthesis is an area where evidence is pretty scarce. He remarked on the fact that the changing pattern of tooth loss results in younger dentists having less and less experience of complete dentures, which he anticipated might become a specialist treatment in future.

In an amusing presentation which revealed a wealth of experience, he demonstrated a compassionate regard for patients. We should not advise them to studs, results in the same effect on an upper ridge as being opposed by natural teeth. It becomes flabby. For those patients who still think dentures are what they want, he reminded his audience of the fact that complete dentures produce only $16 \%$ of the biting efficiency of natural teeth, implants give $85 \%$; "a complete denture is not a substitute for natural teeth. It is a substitute for no teeth."

\section{Work/life balance}

Not all the lectures were on clinical matters, and there was a large audience for Ben Renshaw, star of the TV documentaries 'How to be happy' and 'The stress busters'. His theme was work/life balance, and he tackled the somewhat delicate topic of 'waiting to be happy'. He warned 


\section{DENTAL CONFERENCE}

his audience that working might be killing them' and posed the challenge, "How can we change now?" This was, predictably, an interactive session and those present came up with some immediate responses. Using a diagrammatic 'wheel of life', delegates scored their involvement on eight parameters such as work, spirituality, health, family and learning and were invited to look at the result.

For me and for both my neighbours the 'work' axis heavily out scored the others. "High flyers are fast fallers" he warned, "We need balance." Dr Mike Ellison, Rep Board and LDC member from Worcester, rated the presentation as very good and said that it compared well with similar sessions he had attended. Ben Renshaw advised that we must not let the chores take over and that letting the balance between effort and efficiency get distorted can result in illness, breakdown and exhaustion. Serious stuff indeed.

\section{Workshops}

As with previous BDA conferences there was the usual comprehensive range of workshops and special interest sessions. Professor Liz Kay had a capacity audience for her 'customer care' session and for 'neuro-linguistic programming' for the Women in Dentistry's lunch and learn. At the latter she showed how the understanding generated by this technique had "changed her life" and made rapport with patients so much more predictable. Once this is achieved they can be helped to accept for themselves our messages about oral health.

The sedation and general anaesthetic presentations drew an enthusiastic

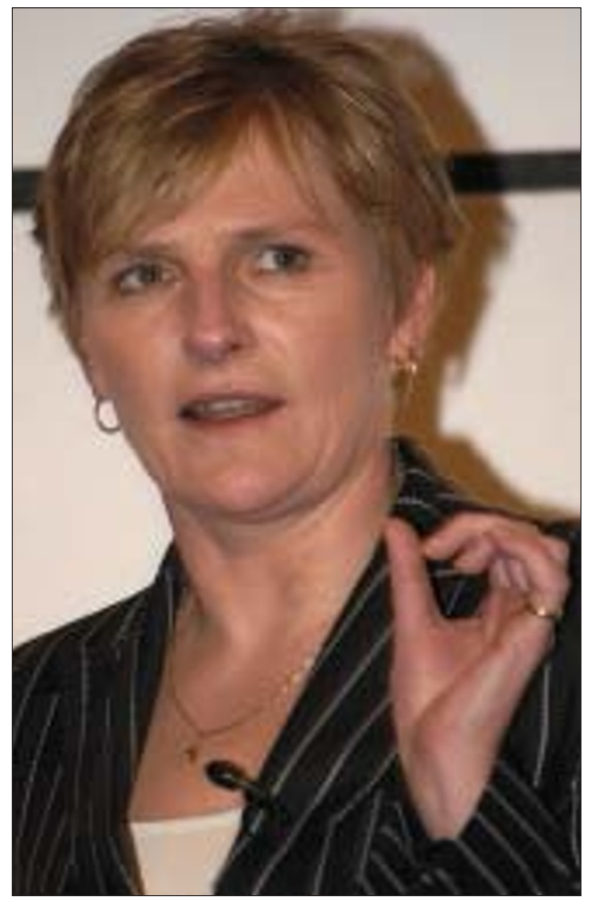

Liz Kay on Customer Care

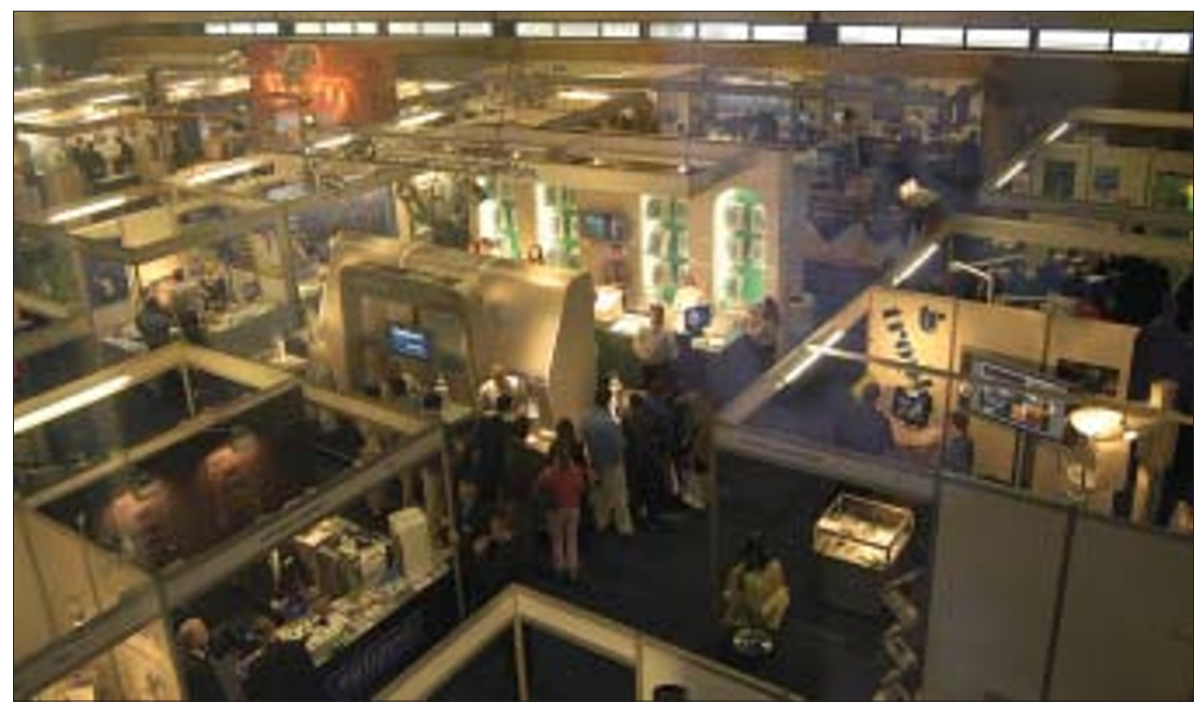

The conference stands

response from delegates, with the speaker in this session asserting that "planning a GA is not a defeat, there is a real need for it for some patients". I feel that this is something that has been somewhat lost sight of in recent reforms. "I really miss access to GA", lamented Dr Sarah Pinkerton from Lisburn.

One of the expected star turns of the conference, the 'farewell, final appearance on the lecture circuit' of Dr Paddi Lund from Australia turned out to be less than 'dynamic and inspirational' for some of his audience. Many attendees complained of a slow start, lack of energy and few practical ideas. Problems due to travel and fatigue may have contributed to a lacklustre performance, but in the "I did it my way" category sparkle has to substitute for evidence and the light seemed a bit dim. Perhaps this is why Paddi is forsaking the podium.

\section{Official premier sponsors of the event included: \\ GlaxoSmithKline \\ Philips Oral Healthcare \\ Other official sponsors of the event included: \\ Braun Oral-B \\ Dental Protection Ltd \\ Dentists' Provident Society}

Bournemouth next year? Let's hope the sun shines so we won't need the free Colgate umbrellas that this year's delegates were glad of when the skies of Manchester predictably opened. Perhaps a sponsor could try some sympathetic magic and hand out complimentary shades!

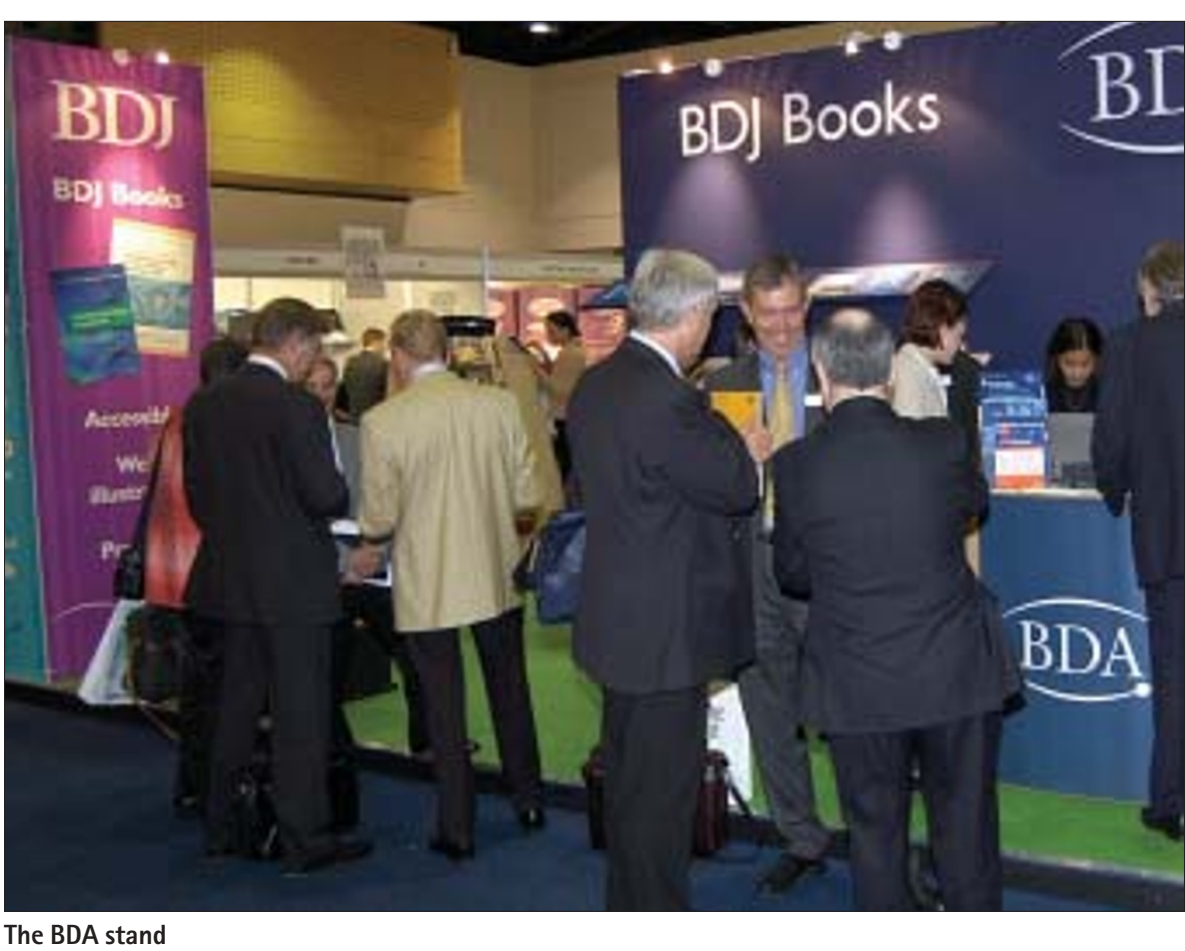

